\title{
Article \\ Effect of Preoperative Anxiety on Postoperative Pain after Craniotomy
}

\author{
Lucía Valencia ${ }^{1, * \mathbb{D}}$, Ángel Becerra ${ }^{1,2}{ }^{\oplus}$, Nazario Ojeda ${ }^{1}$, Ancor Domínguez $^{1}$, Marcos Prados $^{1}$, \\ Jesús María González-Martín ${ }^{3}$ (i) and Aurelio Rodríguez-Pérez ${ }^{1,2}$ () \\ 1 Department of Anesthesiology, University Hospital of Gran Canaria Doctor Negrín, \\ 35010 Las Palmas de Gran Canaria, Spain; angbecbol@gmail.com (Á.B.); \\ nojebet@gobiernodecanarias.org (N.O.); ancor.dominguez@gmail.com (A.D.); \\ marcospm_9@hotmail.com (M.P.); arodperp@gobiernodecanarias.org (A.R.-P.) \\ 2 Department of Medical and Surgical Sciences, University of Las Palmas de Gran Canaria, \\ 35016 Las Palmas de Gran Canaria, Spain \\ 3 Research Unit, University Hospital of Gran Canaria Doctor Negrín, 35010 Las Palmas de Gran Canaria, Spain; \\ josu.estadistica@gmail.com \\ * Correspondence: ori98es@yahoo.es
}

Citation: Valencia, L.; Becerra, Á.; Ojeda, N.; Domínguez, A.; Prados, M.; González-Martín, J.M.; Rodríguez-Pérez, A. Effect of Preoperative Anxiety on Postoperative Pain after Craniotomy. J. Clin. Med. 2022, 11, 556. https:// doi.org/10.3390/jcm11030556

Academic Editor: Rafael Badenes

Received: 23 December 2021

Accepted: 20 January 2022

Published: 22 January 2022

Publisher's Note: MDPI stays neutral with regard to jurisdictional claims in published maps and institutional affiliations.

Copyright: (c) 2022 by the authors. Licensee MDPI, Basel, Switzerland. This article is an open access article distributed under the terms and conditions of the Creative Commons Attribution (CC BY) license (https:// creativecommons.org/licenses/by/ $4.0 /)$.

\begin{abstract}
Pain following craniotomy is challenging. Preoperative anxiety can be one of the controllable factors for prevention of post-craniotomy pain. The main objective of this prospective observational study is to determine this relationship in patients undergoing scheduled craniotomy from February to June 2021. After excluding patients with Mini-Mental State Examination (MMSE) $\leq 24$ points, we administered a preoperative State Trait Anxiety Inventory (STAI) questionnaire. We recorded the patient's analgesic assessment using the Numerical Rating Score (NRS) at 1, 8, 24, and $48 \mathrm{~h}$ after surgery. A total of 73 patients were included in the study. Twelve others were excluded due to a MMSE $\leq 24$ points. The main predictors for NRS postoperatively at $1,8,24$, and $48 \mathrm{~h}$ were STAI A/E score, male gender, youth, and depression. We identified a cut-off point of 24.5 in STAI A/E for predicting a NRS > 3 (sensitivity $82 \%$ and specificity $65 \%$ ) at $24 \mathrm{~h}$ postoperative and a cut-off of 31.5 in STAI A/R (sensitivity $64 \%$ and specificity $77 \%$ ). In conclusion, preoperative STAI scores could be a useful tool for predicting which patient will experience at least moderate pain after craniotomy. The identification of these patients may allow us to highlight psychological preparation and adjuvant analgesia.
\end{abstract}

Keywords: pain; anxiety; craniotomy

\section{Introduction}

Craniotomy has been considered less painful than other surgical interventions because of the lack of nociceptors in the brain tissue. However, we now know that this is not true. The incidence of postoperative pain is high, and its intensity can range from moderate to severe [1]. Recent studies as well as expert opinions confirm that post-craniotomy pain has been under-treated and poorly managed [2-4].

Inadequate management of acute postoperative pain is deleterious since it increases morbidity, changes in quality of life, functionality, and delays in recovery time. It is also unfavorable for the healthcare system because it increases costs [5]. Specifically, postoperative pain can have harmful consequences in neurosurgical patients as it may imply the development of postoperative agitation and the elevation of blood pressure levels. This increases the risk of postoperative cerebral hemorrhage [4]. Furthermore, poor acute pain control in these patients increases the risk of chronic headaches, with an incidence of up to $23 \%$ to $34 \%$ three months after the intervention [1]. Therefore, management of acute pain after craniotomy must be meticulous. 
One of the controllable factors for prevention of post-craniotomy pain is preoperative anxiety. A relationship between preoperative anxiety and acute postoperative pain in surgeries other than craniotomies has been defined [6]. Anxiety may be higher in neurosurgery since neurosurgical patients face not only cancer, but also the fear of developing neurological squeals $[7,8]$. The presence of preoperative anxiety in neurosurgical patients is associated with a poorer quality of life, cognitive performance, memory and attention capacity, longer hospitalization time, depression, and increased physical disability. However, the relationship between preoperative anxiety and the development of postoperative pain has not been studied sufficiently [9].

The main objective of this prospective observational study is to determine the relationship between preoperative anxiety and postoperative pain in patients undergoing scheduled craniotomy under general anesthesia. As secondary objectives, we assess preoperative risk factors for preoperative anxiety, and which perioperative variables can predispose a patient to suffer from greater postoperative pain.

\section{Materials and Methods}

This prospective observational study evaluated preoperative anxiety and postoperative pain in patients scheduled to undergo craniotomy in a university hospital from February to June 2021. The study was approved by the Ethics Committee of Hospital Universitario de Gran Canaria Doctor Negrín, Las Palmas de Gran Canaria, Spain (approval \#2019-241-1, Chairperson Dr. Fiuza), and prospectively registered at Clinicaltrials.gov, accessed on 22 December 2021 (NCT04720248). All methods followed good clinical practice. All patients over 18 years old who were to undergo scheduled supratentorial craniotomy and who signed informed consent were included. Exclusion criteria were: patients suffering from disabilities or cognitive impairment defined as a score $\leq 24$ points in the Mini-Mental State Examination (MMSE), or patients who could not collaborate on the postoperative clinical assessment. This manuscript follows the STROBE guidelines [10].

\subsection{Outcomes}

Preoperative anxiety was evaluated using the Anxiety Scale State-Trait Anxiety Inventory (STAI), a questionnaire developed by Spielberg et al. in 1970 [11]. A Spanish version of STAI has been validated for the Spanish population [12]. This questionnaire is considered an instrument to study anxiety through a self-evaluation of two independent concepts: State Anxiety and Trait Anxiety. State Anxiety (STAI A/E) is conceptualized as a transitory emotional condition characterized by tension, apprehension, and hyperarousal of the Autonomous Nervous System. It can vary in intensity and fluctuate over time. Trait Anxiety (STAI A/R) is characterized by a stable anxious propensity due to the subject's tendency to perceive everyday situations as threatening, thus causing an increase in the degree of anxiety. As anxiety is a subjective quality dependent on age and gender, it has been established that a STAI score of 20 corresponds to the 50th percentile in the adult population [13]. Postoperative pain was assessed per protocol by the Acute Pain Unit using the Numerical Rating Score (NRS), measuring pain from 0 (no pain) to 10 (maximum pain imaginable).

\subsection{Study Protocol}

Upon hospital admission, an independent investigator performed the MMSE. If the score in this examination was higher than or equal to 24 points, preoperative anxiety was evaluated using the STAI questionnaire. After administering the STAI questionnaire, patients were instructed on how to perform postoperative NRS to evaluate postoperative pain. Demographic preoperative data were collected: age, gender, weight, height, body mass index (BMI), educational level (dichotomized as elementary education or higher education), and physical status score according to the American Society of Anesthesiologists (ASA) (from 1 to 5). The patient's medical history was also recorded: depression, anxiety, rheumatological illnesses, and previous use of drugs such as metamizole, corticosteroids, 
antidepressants, and chronic use of analgesics. Histopathological results of the craniotomy were also collected.

All patients underwent elective craniotomy under general anesthesia. The diagnostic (vascular or tumoral) and the type of craniotomy was recorded according to the surgical incision (whether it was frontal/temporal or parietal/occipital), as well as the duration of the intervention. Intraoperative anesthetic management was carried out according to standard clinical practice. Patients were monitored with electrocardiogram, peripheral oxygen saturation, invasive arterial pressure, and bispectral index (BIS, Covidien, Dublin, Ireland). General anesthesia was performed using continuous propofol infusion to maintain BIS $40-60$, using cisatracurium in bolus $\left(0.2 \mathrm{mg} \cdot \mathrm{kg}^{-1}\right)$ to allow orotracheal intubation and in continuous infusion during surgery to ensure intraoperative immobility. As analgesics, continuous infusion of remifentanil or boluses of fentanyl or tramadol were used following clinical practice to maintain intraoperative hemodynamic stability. Patients also received intraoperative non-opioid analgesic drugs (metamizole or paracetamol). If corticosteroids were given intraoperatively, it was also recorded along with the dosage. At the end of the surgery, the neuromuscular blockade was reversed and the tracheal tube was removed. The appearance of intraoperative complications and the placement or not of drains were recorded. The anesthesiologist in charge of the intraoperative management of the patient was not aware that the patient was participating in a study evaluating postoperative analgesia. Patients were transferred to the postoperative Intensive Care Unit (ICU) under the care of an independent clinician. They were transferred to the surgical ward $24 \mathrm{~h}$ after the surgery. In the absence of allergies, all patients received an endovenous continuous infusion of metamizole $12 \mathrm{~g}$ during the first 48 postoperative hours. If patients were allergic to metamizole, paracetamol $1 \mathrm{~g}$ each $6 \mathrm{~h}$ was prescribed. An investigator, who was blinded to the patient's preoperative anxiety assessment, collected the patient's analgesic assessment using NRS at 1, 8, 24, and $48 \mathrm{~h}$ after surgery. Follow-up ended $48 \mathrm{~h}$ postoperatively.

\subsection{Statistical Analysis}

Data were analyzed using the statistical program R Core Team 2021, version 4.1.0 Vienna, Austria. Data on quantitative variables are expressed as mean, standard deviation, median, and 25-75th percentiles. The Kolmogorov test was used to verify the normality of the data. Qualitative variables are described as absolute and relative frequencies. The TStudent test was used to compare quantitative variables between two groups, and Fisher's exact test was used to check the relationship between qualitative variables. Multiple linear regression was used to predict quantitative variables. To perform the predictive model for the NRS variable at $1,8,24$, and $48 \mathrm{~h}$ after surgery, the following variables were analyzed: STAI A/E, STAI A/R, age, female gender, tumoral diagnostic, ASA physical status 3-4, higher educational level, suffering from rheumatological illnesses, depression, or anxiety, previous use of metamizole and corticosteroids, BMI, MMSE, parietal/occipital craniotomy, length of surgery, placement of drains at the end of surgery, and the use of intraoperative corticoids dichotomized into $4 \mathrm{mg}$ or more than $4 \mathrm{mg}$. The forward-backward technique was used to select the optimal model. To check the multicollinearity of the variables, VIF statistic was used, and it was valid if this was lower than 7. The area under the curve (AUC) was calculated to find the best cut-off values of the STAI A/E and STAI A/R to predict the NRS $\geq 3$ at the first and $24 \mathrm{~h}$ postoperatively and expressed as AUC. Sensitivity and specificity were calculated to choose the best cut-off values. A $p$-value $<0.05$ was considered statistically significant.

\section{Results}

From the 85 patients assessed for eligibility during the study period, 12 were excluded due to a score of $\leq 24$ points in the MMSE. Consequently, 73 patients were included in the study. The characteristics of the patients and the intraoperative variables are summarized in Table 1. No statistically significant differences were found between the preoperative 
characteristics of patients regarding the STAI A/E and STAI A/R values dichotomized into less than 20 or more than or equal to 20 (Tables 2 and 3).

Table 1. Characteristics of patients and intraoperative variables.

\begin{tabular}{|c|c|}
\hline & $\begin{array}{l}\text { Study Population } \\
\qquad(n=73)\end{array}$ \\
\hline Age, years & $55 \pm 15$ \\
\hline Female, No. (\%) & $45(61.6)$ \\
\hline $\mathrm{BMI}, \mathrm{kg} \cdot \mathrm{m}^{-1}$ & $24.9 \pm 5.5$ \\
\hline ASA 3, No. (\%) & $38(52.1)$ \\
\hline \multicolumn{2}{|l|}{ Medical history } \\
\hline Depression, No. $(\%)$ & $16(21.9)$ \\
\hline Anxiety, No. (\%) & $5(6.9)$ \\
\hline Rheumatological diseases, No. (\%) & $4(5.5)$ \\
\hline \multicolumn{2}{|l|}{ Previous use of drugs } \\
\hline Metamizole, No. (\%) & $27(36.9)$ \\
\hline Corticosteroids, No. (\%) & $22(30.1)$ \\
\hline Antidepressants, No. (\%) & $14(19.2)$ \\
\hline Chronic use of analgesics, No. (\%) & $12(16.4)$ \\
\hline Educational level: Basic elementary education, No. (\%) & $43(58.9)$ \\
\hline MMSE, points & $28.9 \pm 1.3$ \\
\hline STAI A/E, score & $22.4 \pm 10.8$ \\
\hline STAI A/R, score & $26.9 \pm 7.5$ \\
\hline Main diagnosis: tumoral, No. (\%) & $68(93.2)$ \\
\hline Craniotomy frontal/temporal, No. (\%) & $51(69.9)$ \\
\hline Length of surgery, $\min$ & $241 \pm 89$ \\
\hline \multicolumn{2}{|l|}{ Intraoperative drugs } \\
\hline Remifentanil $0.1 \mathrm{mcg} \cdot \mathrm{kg}^{-1} \cdot \mathrm{min}^{-1}$, No. $(\%)$ & $27(37.0)$ \\
\hline Remifentanil $0.1 \mathrm{mcg} \cdot \mathrm{kg}^{-1} \cdot \mathrm{min}^{-1}+$ Fentanyl, No. (\%) & $42(57.5)$ \\
\hline Remifentanil $0.1 \mathrm{mcg} \cdot \mathrm{kg}^{-1} \cdot \mathrm{min}^{-1}+$ Tramadol, No. $(\%)$ & $4(5.5)$ \\
\hline Not remifentanil, No. (\%) & $19(26.0)$ \\
\hline Dexamethasone $4 \mathrm{mg}$, No. (\%) & $29(39.7)$ \\
\hline Dexamethasone $>4 \mathrm{mg}$, No. $(\%)$ & $25(34.3)$ \\
\hline Postoperative drain $(\%)$ & $45(61.6)$ \\
\hline
\end{tabular}

Data are expressed as mean + SD, or frequency (\%). BMI: body mass index; ASA: American Society of Anesthesiologists; MMSE: Mini-Mental State Examination; STAI A/E: State-Trait Anxiety Inventory State Anxiety; STAI A/R: State-Trait Anxiety Inventory Trait Anxiety.

Table 2. Comparison of preoperative characteristics of patients between STAI A/E $<20$ or $>20$.

\begin{tabular}{|c|c|c|c|}
\hline Variable & $\begin{array}{c}\text { STAI A/E }<20 \\
(N=29)\end{array}$ & $\begin{array}{l}\text { STAI A/E } \geq 20 \\
(N=44)\end{array}$ & $p$-Value \\
\hline $\begin{array}{l}\text { Age, years } \\
\text { Gender }\end{array}$ & $58 \pm 15$ & $54 \pm 15$ & 0.250 \\
\hline $\begin{array}{l}\text { Female, No. (\%) } \\
\text { Male, No. (\%) }\end{array}$ & $\begin{array}{l}16(55.2) \\
13(44.8)\end{array}$ & $\begin{array}{l}29(65.9) \\
15(34.1)\end{array}$ & 0.462 \\
\hline $\mathrm{BMI}, \mathrm{kg} \cdot \mathrm{m}^{-1}$ & $24.6 \pm 4.7$ & $25.0 \pm 6.1$ & 0.767 \\
\hline $\begin{array}{l}\text { Educational level } \\
\qquad \text { Basic elementary, No. (\%) } \\
\text { Other No. (\%) }\end{array}$ & $\begin{array}{l}20(69.0) \\
9(31.0) \\
290+11\end{array}$ & $\begin{array}{c}23(52.3) \\
21(47.7) \\
28.9+15\end{array}$ & 0.224 \\
\hline $\begin{array}{l}\text { Medicalhistory } \\
\text { Depression, No. (\%) } \\
\text { Anxiety, No. (\%) } \\
\text { Rheumatological diseases, No. (\%) }\end{array}$ & $\begin{array}{l}5(17.2) \\
2(6.9) \\
2(6.9)\end{array}$ & $\begin{array}{l}11(25) \\
3(6.8) \\
2(4.5)\end{array}$ & $\begin{array}{c}0.567 \\
1.000 \\
0.66\end{array}$ \\
\hline $\begin{array}{l}\text { Previous useof drugs } \\
\text { Metamizole, No. }(\%) \\
\text { Corticosteroids, No. }(\%) \\
\text { Antidepressants, No. (\%) } \\
\text { Chronic use of analgesics, No. (\%) }\end{array}$ & $\begin{array}{l}8(27.6) \\
6(20.7) \\
6(20.7) \\
7(24.1)\end{array}$ & $\begin{array}{l}19(43.2) \\
16(36.4) \\
8(18.2) \\
5(11.4)\end{array}$ & $\begin{array}{l}0.220 \\
0.197 \\
1.000 \\
0.200\end{array}$ \\
\hline
\end{tabular}

Data are expressed as mean + SD, or frequency (\%). STAI A/E: State-Trait Anxiety Inventory State Anxiety; BMI: body mass index; MMSE: Mini-Mental State Examination. 
Table 3. Comparison of preoperative characteristics of patients between STAI A/R $<20$ or $>20$.

\begin{tabular}{|c|c|c|c|}
\hline Variable & $\begin{array}{c}\text { STAI A/R }<20 \\
\quad(N=10)\end{array}$ & $\begin{array}{c}\text { STAI A } / R \geq 20 \\
(N=63)\end{array}$ & $p$-Value \\
\hline Age, years & $53 \pm 18$ & $56 \pm 14$ & 0.659 \\
\hline \multicolumn{4}{|l|}{ Gender } \\
\hline Female, No. $(\%)$ & $5(50)$ & $23(36.5)$ & \multirow{2}{*}{0.492} \\
\hline Male, No. (\%) & $5(50)$ & $40(63.5)$ & \\
\hline $\mathrm{BMI}, \mathrm{kg} \cdot \mathrm{m}^{-1}$ & $25.7 \pm 4.3$ & $24.7 \pm 5.7$ & 0.480 \\
\hline \multicolumn{4}{|l|}{ Educational level } \\
\hline Basic elementary education, No. $(\%)$ & $7(70)$ & $36(57.1)$ & \multirow{2}{*}{0.510} \\
\hline Other, No. $(\%)$ & $3(30)$ & $27(42.9)$ & \\
\hline MMSE, points & $29.1 \pm 0.9$ & $28.9 \pm 1.4$ & 0.885 \\
\hline \multicolumn{4}{|l|}{ Medicalhistory } \\
\hline Depression, No. (\%) & $1(10)$ & $15(23.8)$ & 0.443 \\
\hline Anxiety, No. (\%) & $1(10)$ & $4(6.3)$ & 0.532 \\
\hline Rheumatological diseases, No. (\%) & $1(10)$ & $3(4.8)$ & 0.499 \\
\hline \multicolumn{4}{|l|}{ Previous use of drugs } \\
\hline Metamizole, No. (\%) & $4(40)$ & $23(36.5)$ & 1.000 \\
\hline Corticosteroids, No. (\%) & $1(10)$ & $21(33.3)$ & 0.264 \\
\hline Antidepressants, No. (\%) & $2(20)$ & $12(19)$ & 1.000 \\
\hline Chronic use of analgesics, No. (\%) & $2(20)$ & $10(15.9)$ & 0.665 \\
\hline
\end{tabular}

Data are expressed as mean + SD, or frequency (\%). STAI A/R: State-Trait Anxiety Inventory Trait Anxiety; BMI: body mass index; MMSE: Mini-Mental State Examination.

The incidence of nausea was $1.4 \%$. No postoperative vomiting was recorded. Pain assessment was performed postoperatively on all patients. The mean NRS was $3.26+1.97$ at the first hour, $2.56+1.71$ at $8 \mathrm{~h}, 2.04+1.46$ at $24 \mathrm{~h}$, and $1.84+1.20$ at $48 \mathrm{~h}$. The optimal variables to predict postoperative NRS were calculated. The optimal variables found were: STAI A/E, age, female gender, ASA physical status 3-4, depression, and MMSE for NRS at the first postoperative hour; STAI A/E, age, female gender, depression, parietal/occipital craniotomy, and length of surgery for the NRS at 8 postoperative hours; STAI A/E, age, female gender, ASA physical status 3-4, depression, parietal/occipital craniotomy, and length of surgery for the NRS at 24 postoperative hours; and STAI A/E, age, length of surgery, and use of intraoperative dexamethasone for NRS at 48 postoperative hours. Tables 4 and 5 show the coefficients of the univariate and multivariate analyses of the variables that influence the different NRS evaluated in the postoperative period.

Table 4. Main predictors for NRS 1 and $4 \mathrm{~h}$ postoperatively.

\begin{tabular}{|c|c|c|c|c|c|c|c|c|}
\hline \multirow[b]{2}{*}{ Variable } & \multicolumn{4}{|c|}{ NRS at $1 \mathrm{~h}$} & \multicolumn{4}{|c|}{$\mathrm{NRS}$ at $8 \mathrm{~h}$} \\
\hline & Univariate & $p$-Value & Multivariate & $p$-Value & Univariate & $p$-Value & Multivariate & $p$-Value \\
\hline STAI A/E & $\begin{array}{c}0.08 \\
(0.04-0.11)\end{array}$ & $<0.001$ & $\begin{array}{c}0.06 \\
(0.02-0.1)\end{array}$ & 0.003 & $\begin{array}{c}0.04 \\
(0.01-0.08)\end{array}$ & 0.024 & $\begin{array}{c}0.04 \\
(0-0.08)\end{array}$ & 0.029 \\
\hline STAI A/R & $\begin{array}{c}0.05 \\
(-0.01-0.11)\end{array}$ & 0.09 & $\begin{array}{c}-0.01 \\
(-0.07-0.05)\end{array}$ & 0.76 & $\begin{array}{c}0.04 \\
00280.01-0.09)\end{array}$ & 0.13 & $\begin{array}{c}0.03 \\
00280.06-0.06)\end{array}$ & 0.968 \\
\hline Age & $\begin{array}{l}-0.06 \\
(-0.09- \\
-0.03)\end{array}$ & $<0.001$ & $\begin{array}{c}-0.07 \\
(-0.1--0.04)\end{array}$ & $<0.001$ & $\begin{array}{c}-0.04 \\
(-0.07--0.02)\end{array}$ & 0.001 & $\begin{array}{c}-0.05 \\
(-0.08--0.03)\end{array}$ & $<0.001$ \\
\hline Female gender & $\begin{array}{c}0.07 \\
(-0.88-1.02)\end{array}$ & 0.88 & $\begin{array}{c}-0.7 \\
(-1.55-0.15)\end{array}$ & 0.11 & $\begin{array}{c}-0.19 \\
(-1.01-0.63)\end{array}$ & 0.648 & $\begin{array}{c}-0.72 \\
(-1.5-0.06)\end{array}$ & 0.068 \\
\hline Depression & $\begin{array}{c}0.23 \\
(-0.89-1.34)\end{array}$ & 0.69 & $\begin{array}{c}0.93 \\
(-0.05-1.9)\end{array}$ & 0.06 & $\begin{array}{c}0.8 \\
(-0.15-1.75)\end{array}$ & 0.097 & $\begin{array}{c}1.48 \\
(0.6-2.36)\end{array}$ & 0.001 \\
\hline $\begin{array}{c}\text { ASA physical status } \\
3-4\end{array}$ & $\begin{array}{c}0.32 \\
(-0.6-1.24)\end{array}$ & 0.49 & $\begin{array}{c}0.63 \\
(-0.13-1.4)\end{array}$ & 0.1 & - & - & - & - \\
\hline
\end{tabular}


Table 4. Cont.

\begin{tabular}{|c|c|c|c|c|c|c|c|c|}
\hline \multirow[b]{2}{*}{ Variable } & \multicolumn{4}{|c|}{ NRS at $1 \mathrm{~h}$} & \multicolumn{4}{|c|}{ NRS at $8 \mathrm{~h}$} \\
\hline & Univariate & $p$-Value & Multivariate & $p$-Value & Univariate & $p$-Value & Multivariate & $p$-Value \\
\hline MMSE & $\begin{array}{c}-0.03 \\
(-0.38-0.32)\end{array}$ & 0.87 & $\begin{array}{c}-0.25 \\
(-0.56-0.06)\end{array}$ & 0.11 & - & - & - & - \\
\hline $\begin{array}{l}\text { Parietal/occipital } \\
\text { craniotomy }\end{array}$ & 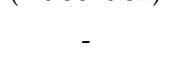 & - & - & - & $\begin{array}{c}0.04 \\
(-0.83-0.92)\end{array}$ & 0.924 & $\begin{array}{c}0.76 \\
(-0.02-1.54)\end{array}$ & 0.056 \\
\hline Length of surgery & - & - & - & - & $\begin{array}{c}0 \\
(-0.01-0)\end{array}$ & 0.138 & $\begin{array}{l}-0.003 \\
(-0.01-0)\end{array}$ & 0.163 \\
\hline
\end{tabular}

Data are expressed as coefficient (95\% CI). NRS: Numerical Rating Score; STAI A/E: State-Trait Anxiety Inventory State Anxiety; STAI A/R: State-Trait Anxiety Inventory Trait Anxiety; MMSE: Mini-Mental State Examination; ASA: American Society of Anesthesiologists.

Table 5. Main predictors for NRS 24 and $48 \mathrm{~h}$ postoperatively.

\begin{tabular}{|c|c|c|c|c|c|c|c|c|}
\hline \multirow[b]{2}{*}{ Variable } & \multicolumn{4}{|c|}{ NRS at $24 \mathrm{~h}$} & \multicolumn{4}{|c|}{ NRS at $48 \mathrm{~h}$} \\
\hline & Univariate & $p$-Value & Multivariate & $p$-Value & Univariate & $p$-Value & Multivariate & $p$-Value \\
\hline STAI A/E & $\begin{array}{c}0.04 \\
(0.01-0.07)\end{array}$ & 0.018 & $\begin{array}{c}0.04 \\
(0-0.07)\end{array}$ & 0.029 & $\begin{array}{c}0.03 \\
(0-0.05)\end{array}$ & 0.053 & $\begin{array}{c}0.02 \\
(0-0.05)\end{array}$ & 0.078 \\
\hline STAI A/R & $\begin{array}{c}0.04 \\
(-0.01-0.08)\end{array}$ & 0.083 & $\begin{array}{c}0.02 \\
(-0.03-0.07)\end{array}$ & 0.502 & $\begin{array}{c}0.04 \\
(0-0.07)\end{array}$ & 0.061 & $\begin{array}{c}0.01 \\
(-0.03-0.06)\end{array}$ & 0.53 \\
\hline Age & $\begin{array}{c}-0.04 \\
(0.06--0.02)\end{array}$ & $<0.001$ & $\begin{array}{l}-0.04 \\
(-0.06- \\
-0.02)\end{array}$ & $<0.001$ & $\begin{array}{c}-0.02 \\
(-0.04-0)\end{array}$ & 0.069 & $\begin{array}{c}-0.01 \\
(-0.03-0)\end{array}$ & 0.145 \\
\hline Female gender & $\begin{array}{c}-0.11 \\
(-0.81-0.6)\end{array}$ & 0.762 & $\begin{array}{c}-0.48 \\
(-1.17-0.22)\end{array}$ & 0.17 & - & - & - & - \\
\hline Depression & $\begin{array}{c}0.11 \\
(-0.72-0.93)\end{array}$ & 0.796 & $\begin{array}{c}0.61 \\
(-0.17-1.39)\end{array}$ & 0.12 & - & - & - & - \\
\hline $\begin{array}{c}\text { ASA physical status } \\
3-4\end{array}$ & $\begin{array}{c}0.35 \\
(-0.33-1.03)\end{array}$ & 0.306 & $\begin{array}{c}0.44 \\
(-0.17-1.06)\end{array}$ & 0.153 & - & - & - & - \\
\hline $\begin{array}{l}\text { Parietal/occipital } \\
\text { craniotomy }\end{array}$ & $\begin{array}{c}0.01 \\
(-0.74-0.75)\end{array}$ & 0.987 & $\begin{array}{c}0.54 \\
(-0.15-1.24)\end{array}$ & 0.123 & - & - & - & - \\
\hline Length of surgery & $\begin{array}{c}0 \\
(-0.01-0)\end{array}$ & 0.02 & $\begin{array}{l}-0.002 \\
(-0.01-0)\end{array}$ & 0.183 & $\begin{array}{c}0 \\
(-0.01-0)\end{array}$ & 0.009 & $\begin{array}{c}-0.003 \\
(-0.01-0)\end{array}$ & 0.025 \\
\hline $\begin{array}{c}\text { Intraoperative } \\
\text { dexamethasone } 4 \mathrm{mg}\end{array}$ & - & - & (1) & - & $\begin{array}{c}-0.83 \\
(-1.52--0.14)\end{array}$ & 0.019 & $\begin{array}{c}-0.76 \\
(-1.42--0.1)\end{array}$ & 0.025 \\
\hline $\begin{array}{c}\text { Intraoperative } \\
\text { dexamethasone }>4 \mathrm{mg}\end{array}$ & - & - & - & - & $\begin{array}{c}-0.44 \\
(-1.15-0.28)\end{array}$ & 0.226 & $\begin{array}{c}-0.39 \\
(-1.06-0.29)\end{array}$ & 0.255 \\
\hline
\end{tabular}

Data are expressed as coefficient (95\% CI). NRS: Numerical Rating Score; STAI A/E: State-Trait Anxiety Inventory State Anxiety; STAI A/R: State-Trait Anxiety Inventory Trait Anxiety; ASA: American Society of Anesthesiologists.

We identified that a cut-off point of 24.5 in STAI A/E was the best one to predict NRS $\geq 3$, with an area under the curve (AUC) of 0.60 with sensitivity $62 \%$ and specificity $65 \%$ at the first postoperative hour, and an AUC of 0.69 with a sensitivity $82 \%$ and specificity $65 \%$ at the assessment performed at 24 postoperative hours. However, in the STAI A/R questionnaire, 22.5 was the cut-off point that best defined a NRS greater than 3 in the first postoperative hour, with an AUC of 0.5 and with a sensitivity $33 \%$ and a specificity $77 \%$, and the cut-off point of 31.5 was better to define NRS at 24 postoperative hours with an AUC of 0.68 , sensitivity $64 \%$, and specificity of $77 \%$ (Figures 1 and 2, ROC curves). 

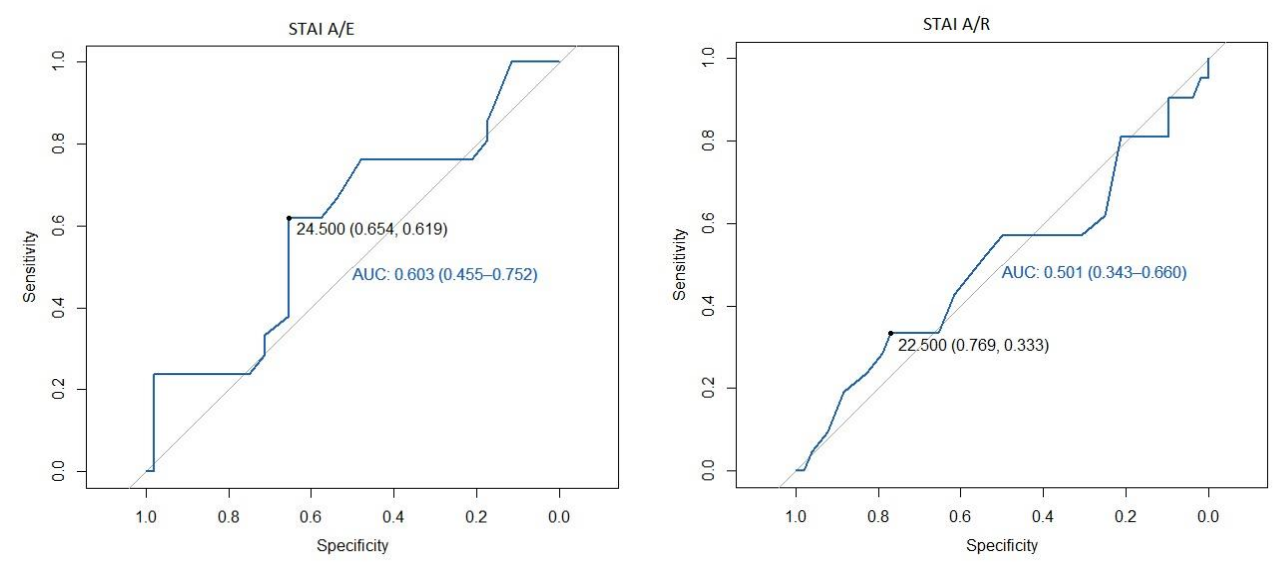

Figure 1. ROC curve of the STAI at $1 \mathrm{~h}$ postoperative as a predictor of mild pain. STAI A/E: State-Trait Anxiety Inventory State Anxiety; STAI A/R: State-Trait Anxiety Inventory Trait Anxiety; AUC: Area under the curve.
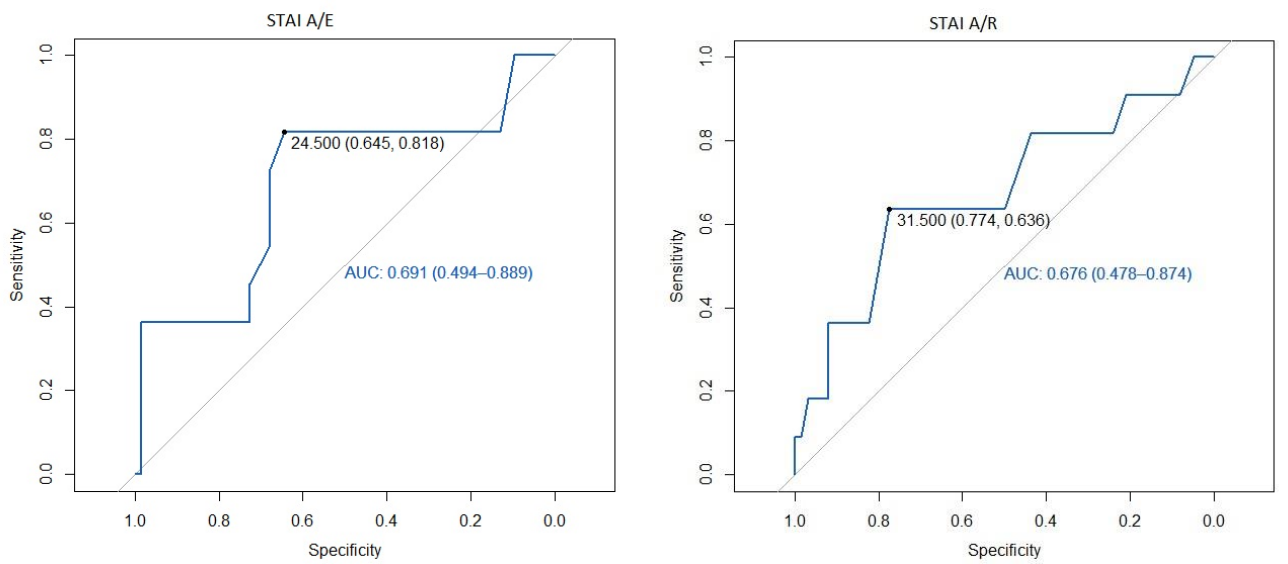

Figure 2. ROC curve of the STAI at $24 \mathrm{~h}$ postoperative as a predictor of mild pain. STAI A/E: State-Trait Anxiety Inventory State Anxiety; STAI A/R: State-Trait Anxiety Inventory Trait Anxiety.

\section{Discussion}

In this prospective observational study, we demonstrated that a STAI A/E score greater than 24.5 predicts which patients will experience at least moderate pain after craniotomy. In addition, we found that the presence of depression, youth, and male gender can worsen postoperative pain. No relationship was found between preoperative variables and anxiety levels.

Postoperative headache is a common complication after surgical procedures other than craniotomy. Several risk factors have been demonstrated to be related to this complication, such as age, female gender, previous history of headache, and anesthetic drugs. On the other hand, post-craniotomy pain is a different and more specific entity. Its management is challenging for anesthesiologists. One of the main reasons for poor therapeutic control is the fear of the side effects of analgesics drugs. The use of opioids can interfere with neurological examination, andnon-steroidal anti-inflammatories (NSAIDs) can increase the risk of bleeding, which is highly dangerous in neurosurgical patients. Given that the pharmacological management of pain control is a challenge, several studies have focused on discovering other variables that could intensify or mitigate pain. Looking for strategies to improve pain control, ERAS (Enhanced Recovery after Surgery) programs have also reached neurosurgery [14]. It has recently been demonstrated that patients included in ERAS programs show, among many other advantages, less postoperative pain [9]. It is interesting to note that the literature reports that acute pain after craniotomy is moderatesevere. However, opioids can be reduced or avoided in ERAS protocols, resulting in 
an even better postoperative pain control. In the ERAS program, patient education to adjust perioperative expectations has been shown to increase patient satisfaction [15]. This intervention might be the reason preoperative anxiety and, consequently, postoperative pain are mitigated. In our study, we have been able to identify those patients who will experience more postoperative pain by using a preoperative anxiety test. These patients could benefit from several actions in order to optimize postoperative control.

On one side, the use of adjunctive therapies could help ameliorate pain. In a recent systematic review of pharmacological interventions for the prevention of acute postoperative pain in adults following craniotomy, it has been indicated that NSAIDs rank first for their efficacy [1]. However, there are alternatives that are gaining strength, and that can reduce postoperative analgesic requirements. Intraoperative use of dexmedetomidine has been demonstrated to improve analgesia management, reducing opioid consumption during the first $24 \mathrm{~h}$ after craniotomy $[16,17]$. Another multimodal analgesic is the scalp block. Although infiltration of the surgical wound with local anesthetics may be easier to perform and have similar efficacy, the analgesic effect offered by scalp block is superior and longer [18].

On the other hand, as we have already mentioned, psychological preparation prior to surgery can reduce postoperative pain due to its psychological component. This may involve several strategies described in previous studies [19]: providing information on the procedures and equipment to be used, talking about care expectations and past stressful experiences, reporting how pain is managed postoperatively with the description of analgesic techniques, and encouraging requesting painkillers. There is a Cochrane systematic review confirming that the use of techniques focused onproviding better psychological preparation areassociated with less postoperative pain, but with low evidence [19]. However, the same authors recommend caution upon interpreting the results. This is due to the heterogeneity of the psychological preparations and outcomes of the articles included in the review, as most were carried out for cardiac and orthopedic surgery. In the field of neurosurgery, there is a study on the psychological consequences of awake craniotomy. This prospective study found a positive correlation between preoperative anxiety according to the Hospital Anxiety and Depression Scale (HADS) and the NRS on the third postoperative day [20]. However, it is striking that, in this study, pain assessment was carried out at the third postoperative day, considering that the highest incidence of pain occurs on the first postoperative day, as we demonstrated in our study. The scarcity of studies in neurosurgery might be due to the difficulty ofachieving a sufficient sample size because neurosurgical procedures account for only $2.6 \%$ of all surgeries [21]. Furthermore, cognitive impairment is highly prevalent in patients undergoing craniotomy [22] as a consequence of the presence of tumor, tumor-related epilepsy, use of corticosteroids, or increased intracranial pressure [23]. Cognitive impairment makes pain and anxiety scales difficult to perform. Thus, in our work, patients with MMSE $\leq 24$ points were excluded.

Regarding the scale chosen to assess anxiety, most prospective studies on preoperative anxiety have used STAI. [11]. However, there are other scales to assess preoperative anxiety. The "Amsterdam preoperative anxiety and information scale" (APAIS) [24] is a scale specifically designed to detect anxiety related to anesthesia and surgery using 6 simple questions. Another scale is HADS [25], which is the international gold standard for assessing anxiety and depression in patients suffering from physical complaints. Both scales, APAIS and HADS, could be reflected into the STAI A/E and STAI A/R questionnaires, respectively; while the APAIS would be the equivalent of the STAI A/E, the HADS would be similar to STAI A/R, since it reflects how the individual feels in a general way. Therefore, the STAI scale is the most adequate since both anxiety as a temporary condition experienced in a specific situation (STAI A/E) as well as anxiety as the generalized tendency to perceive situations as threatening (STAI A/R) can play a role in experiencing postoperative pain $[26,27]$. One study assessed the quality of different instruments to assess preoperative anxiety in neurosurgical patients including STAI, APAIS, or the assessment of anxiety on a numerical 
scale (NRS), concluding that all are valid but that the STAI questionnaire would be the ideal instrument for evaluation ifcase reliability was of particular importance [28].

In this study, we observed that both STAI A/E and STAI A/R are capable of predicting that the patient will experience at least moderate pain at $24 \mathrm{~h}$, with an $82 \%$ and $64 \%$ sensitivity and a $65 \%$ and $77 \%$ specificity, respectively. Given these sensitivity and specificity values, if one of the two had to be chosen, we would select the most sensitive (STA A/E). In addition, the cut-off point of the STAI A/R is too high to be used, so few patients would obtain this score and would benefit from this screening.

Regarding the variables that could affect post-craniotomy pain, we found that the most important was the STAI A/E score. However, we also stated that other factors can influence postoperative pain such as male gender, youth, and depression. Young patients have a higher incidence of pain. Currently, it is known that the probability of experiencing post-craniotomy pain is reduced by $3 \%$ for each year of life [29]. It has been also shown that the presence of anxiety, depression, and postoperative pain can be risk factors for the worsening of post-craniotomy pain [4]. In our study, unlike in other studies, men experienced more pain after craniotomy. No explanation for this finding was found.

Analyzing the risk factors for preoperative anxiety, we did not find a significant relationship with the preoperative variables analyzed. In many studies, women have higher levels of anxiety than men $[9,28]$. We also found a higher percentage of women in the group with the highest STAI, although these differences were not significant. Wedid not find a relationship between preoperative anxiety and histological diagnosis, as in previous articles [9].

We acknowledge some potential limitations in the present study. First, the incidence of chronic pain 3 months postoperatively was not analyzed. Considering the high incidence of chronic pain after craniotomy, this outcome could have been interesting and relevant, since its presence actually reduces the quality of life of our patients. Second, excluding patients using the MMSE may be a quick technique, but could also be inaccurate. It has been reported that cognitive impairment is frequent in patients who are going to undergo craniotomy [23] and for this reason, in our study, $14 \%$ of screened patients were excluded. The use of more comprehensive tests could have excluded more patients with more specific results. However, cognitive deficits secondary to psychological disturbances are also described. Taking into account the relationship that anxiety may have with other psychological disorders, it may have produced a bias in the exclusion of patients with cognitive deficits related to the main variable under study.Third, although the STAI is the most appropriate test to carry out this study, we are aware that the duration of the test (approximately $20 \mathrm{~min}$ ) is rather long. This could lead to inaccurate responses due to patients becoming tired. In addition, this test may be too long for use in routine clinical practice.

\section{Conclusions}

In conclusion, this is the first study in patients scheduled for craniotomy under general anesthesia showing that preoperative STAI scores could be a useful tool for predicting which patient will experience at least moderate pain after craniotomy. The early identification of these patients may allow us to insist on several aspects, such as psychological preparation and adjuvant analgesia. A preoperative visit performed by a specialist (nurse, neurosurgeon, or anesthesiologist) with a psychologist could reduce preoperative anxiety and, thus, influence the appearance of postoperative pain.

Author Contributions: Conceptualization, L.V., Á.B. and A.R.-P.; Data curation, Á.B., N.O., A.D. and M.P.; Formal analysis, Á.B. and J.M.G.-M.; Investigation, L.V., Á.B., N.O., A.D., M.P. and A.R.-P.; Methodology, L.V., Á.B. and J.M.G.-M.; Software, J.M.G.-M.; Writing-original draft, L.V., Á.B. and A.R.-P.; Writing—review and editing, L.V., Á.B., N.O., A.D., M.P., J.M.G.-M. and A.R.-P. All authors have read and agreed to the published version of the manuscript. 
Funding: This research did not receive any specific grant from funding agencies in the public, commercial, or not-for-profit sectors. Support was provided solely from departmental sources. This research received no external funding.

Institutional Review Board Statement: The study was conducted according to the guidelines of the Declaration of Helsinkiand approved by the Ethics Committee of University Hospital of Gran Canaria Doctor Negrín, Las Palmas de Gran Canaria, Spain (EC approval \#2019-241-1) on 25 April 2019.

Informed Consent Statement: Informed consent was obtained from all subjects involved in the study.

Data Availability Statement: The data that support the findings of this study are available upon request to the corresponding authors.

Acknowledgments: The authors thank Acute Pain Unit (Carolina Medina, GemaHernanz, Laura Morales, and Yurena Dominguez). We also thank Department of Neurosurgery (Jesús Morera).

Conflicts of Interest: The authors declare no conflict of interest.

\section{References}

1. Galvin, I.M.; Levy, R.; Day, A.G.; Gilron, I. Interventions for the prevention of acute postoperative pain in adults following brain surgery. Cochrane Database Syst. Rev. 2019, 2019, CD011931. [CrossRef] [PubMed]

2. Kotak, D.; Cheserem, B.; Solth, A. A survey of post-craniotomy analgesia in British neurosurgical centres: Time for perceptions and prescribing to change? Br. J. Neurosurg. 2009, 23, 538-542. [CrossRef] [PubMed]

3. Valero, R.; Carrero, E.; Fàbregas, N.; Iturri, F.; Saiz-Sapena, N.; Valencia, L. National survey on postoperative care and treatment circuits in neurosurgery. Rev. Esp. AnestesiolReanim. 2017, 64, 441-452. [CrossRef]

4. Vacas, S.; Van de Wiele, B. Designing a pain management protocol for craniotomy: A narrative review and consideration of promising practices. Surg. Neurol. Int. 2017, 8, 291. [CrossRef] [PubMed]

5. Gan, T.J. Poorly controlled postoperative pain: Prevalence, consequences, and prevention. J. Pain Res. 2017, 10, 2287-2298. [CrossRef] [PubMed]

6. Yang, M.M.H.; Hartley, R.L.; Leung, A.A.; Ronksley, P.E.; Jetté, N.; Casha, S.; Riva-Cambrin, J. Preoperative predictors of poor acute postoperative pain control: A systematic review and meta-analysis. BMJ Open 2019, 9, e025091. [CrossRef]

7. Carl, R.; Wajer, H.I.; Robe, P.; van Zandvoort, M.L. Anxiety in the pre-operative phase of awake brain tumor surgery. Clin. Neurol. Neurosurg. 2017, 157, 7-10.

8. Perks, A.; Chakravarti, S.; Manninen, P. Preoperative anxiety in neurosurgical patients. J. Neurosurg. Anesthesiol. 2009, 21, 127-130. [CrossRef] [PubMed]

9. Oteri, V.; Martinelli, A.; Crivellaro, E.; Gigli, F. The impact of preoperative anxiety on patients undergoing brain surgery: A systematic review. Neurosurg. Rev. 2021, 44, 3047-3057. [CrossRef] [PubMed]

10. Von Elm, E.; Altman, D.G.; Egger, M.; Pocock, S.J.; Gøtzsche, P.C.; Vandenbroucke, J.P.; STROBE Initiative. The Strengthening the Reporting of Observational Studies in Epidemiology (STROBE) statement: Guidelines for reporting observational studies. Lancet 2007, 370, 1453-1457. [CrossRef]

11. Spielberger, C.D. Assessment of state and trait anxiety: Conceptual and methodological issues. South Psychol. 1985, 2, 6-16.

12. Bermúdez, J. Anxiety and performance. Rev. Psicol. Gen. Apl. 1978, 151, 183-207.

13. Spielberger, C.D.; Gorsuch, R.L.; Lushene, R. Manual del Cuestionario de Ansiedad Estado-Rasgo (STAI); TEA Ediciones: Madrid, Spain, 1982.

14. Vittorio Stumpo, V.; Staartjes, E.; Quddusi, A.; Corniola, M.V.; Tessitore, E.; Schröder, M.L.; Anderer, E.G.; Stienen, M.N.; Serra, S.; Regli, L. Enhanced Recovery After Surgery strategies for elective craniotomy: A systematic review. J. Neurosurg. 2021, 135, 1857-1881. [CrossRef]

15. Liu, B.; Liu, S.; Wang, Y.; Zhao, B.; Zhao, T.; Zhao, L.; Lv, W.; Zhang, Y.; Zheng, T.; Xue, Y.; et al. Neurosurgical enhanced recovery after surgery (ERAS) programme for elective craniotomies: Are patients satisfied with their experiences? A quantitative and qualitative analysis. BMJ Open 2019, 9, e028706. [CrossRef]

16. Peng, K.; Jin, X.H.; Liu, S.L.; Ji, F.H. Effect of intraoperative dexmedetomidine on post-craniotomy pain. Clin. Ther. 2015, 37, 1114-1121.e1. [CrossRef] [PubMed]

17. Song, J.; Ji, Q.; Sun, Q.; Gao, T.; Liu, K.; Li, L. The opioid-sparing effect of intraoperative dexmedetomidine infusion after craniotomy. J. Neurosurg. Anesthesiol. 2016, 28, 14-20. [CrossRef]

18. Iturri, F.; Valencia, L.; Honorato, C.; Martínez, A.; Valero, R.; Fàbregas, N. Narrative review of acute post-craniotomy pain. Concept and strategies for prevention and treatment of pain. Rev. Esp. Anestesiol. Reanim. 2020, 67, 90-98. [CrossRef] [PubMed]

19. Powell, R.; Scott, N.W.; Manyande, A.; Bruce, J.; Vögele, C.; Byrne-Davis, L.M.; Unsworth, M.; Osmer, C.; Johnston, M. Psychological preparation and postoperative outcomes for adults undergoing surgery under general anaesthesia. Cochrane Database Syst. Rev. 2016, 5, CD008646. [CrossRef] [PubMed]

20. Hejrati, N.; Spieler, D.; Samuel, R.; Regli, L.; Weyerbrock, A.; Surbeck, W. Conscious Experience and Psychological Consequences of Awake Craniotomy. World Neurosurg. 2019, 129, e381-e386. [CrossRef] [PubMed] 
21. Peduto, V.A.; Chevallier, P.; Casati, A. A multicenter survey on anaesthesia practice in Italy. Minerva Anestesiol. $2004,70,473-491$.

22. Pranckeviciene, A.; Deltuva, V.P.; Tamasauskas, A.; Bunevicius, A. Association between psychological distress, subjective cognitive complaints and objective neuropsychological functioning in brain tumor patients. Clin. Neurol. Neurosurg. 2017, 163, 18-23. [CrossRef]

23. Taphoorn, M.J.B.; Klein, M. Cognitive deficits in adult patients with brain tumours. Lancet Neurol. 2004, 3, 159-168. [CrossRef]

24. Moerman, N.; van Dam, F.S.; Muller, M.J.; Oosting, H. The Amsterdam preoperative anxiety and information scale (APAIS). Anesth. Analg. 1996, 82, 445-451. [CrossRef] [PubMed]

25. Zigmond, A.S.; Snait, R.P. The hospital anxiety and depression scale. Acta Psychiatr. Scand. 1983, 67, 361-370. [CrossRef] [PubMed]

26. Theunissen, M.; Peters, M.L.; Bruce, J.; Gramke, H.F.; Marcus, M.A. Preoperative anxiety and catastrophizing: A systematic review and meta-analysis of the association with chronic postsurgical pain. Clin. J. Pain 2012, 28, 819-841. [CrossRef]

27. Sobol-Kwapinska, M.; Babel, P.; Plotek, W.; Stelcer, B. Psychological correlates of acute postsurgical pain: A systematic review and meta-analysis. Eur. J. Pain 2016, 20, 1573-1586. [CrossRef] [PubMed]

28. Goebel, S.; Mehdorn, H.M. Assessment of preoperative anxiety in neurosurgical patients: Comparison of widely used measures and recommendations for clinic and research. Clin. Neurol. Neurosurg. 2018, 172, 62-68. [CrossRef]

29. Mordhorst, C.; Latz, B.; Kerz, T.; Wisser, G.; Schmidt, A.; Schneider, A.; Jahn-Eimermacher, A.; Werner, C.; Engelhard, K. Prospective assessment of postoperative pain after craniotomy. J. Neurosurg. Anesthesiol. 2010, 22, 202-206. [CrossRef] 